\title{
Effects of Knowledge of Result Versus Knowledge of Performance on Treadmill Training on gait ability in Stroke Patients: A Randomized Clinical Trial
}

Jin Park

Department of Physical Therapy, Drim Sol Hospital, Jeonju, Korea

Purpose: This study compared the walking ability of chronic stroke patients following either treadmill training with knowledge of the result (KR group) or treadmill training with knowledge of the performance (KP group).

Methods: Nineteen patients with chronic stroke were recruited from a rehabilitation hospital. The patients were divided into two groups: a KR group (10 patients) and a KP group (9 patients). They received 30 minutes of neuro-developmental therapy and treadmill training 30 minutes, five times a week for three weeks. The gait parameters were measured before and after training using the Optogait system.

Results: After the training periods, the KR group showed significant improvement in gait speed, cadence, step length of the unaffected limb, stance time of the affected limb, and functional gait assessment compared to the KP group $(p<0.05)$.

Conclusion: The results showed that treadmill training with KR was more effective in improving the gait speed and cadence, step length of the unaffected limb, stance time of the affected limb, and functional gait ability than the treadmill training with KP. Therefore, to improve the walking ability of stroke patients, it is necessary to consider treadmill training with KR. If it can be combined with conventional neurological physiotherapy, it would be an effective rehabilitation for stroke patients.

Keywords: Feedback, Gait, Knowledge of performance, Knowledge of result, Stroke, Treadmill training.

서 론

뇌졸중이란 뇌혈관의 막힘 또는 출혈의 원인으로 발생되는 질환으 로써 뇌의 기능 소실로 인한 신경학적 손상과 신체적, 심리적 장애를 유발한다. 뇌졸중 발병으로 인하여 뇌 손상부위 반대편이 마비되는 편마비 증상을 유발하고, 지각기능과 인지기능의 소실 등으로 인해 비정상적인 움직임과 협응, 조절 문제를 발생시켜 장기간 운동능력 의 회복이 지연된다.,3 운동능력 회복의 지연은 마비측과 비마비측의 비대칭적인 체중분포와 체중이동 능력을 감소시켜 독립적인 기립자 세를 유지하기 어려우며, 결국 보행 시에도 정상적인 보행이 어려워지 고 일상생활을 영위함에 있어 문제를 초래한다.-6 뇌졸중 환자의 보 행특성을 살펴보면 병변과 관련된 근 골격계와 신경감각계의 문제로 인하여 보행 시 시공간적 요소 및 운동학적 요소의 변형을 나타낸 다.7.8 특히 보행 시 마비측의 제어를 증가시키고 비마비측의 보상작용 을 증가시킴에 따라 비대칭적인 보행의 형태를 나타나게 되고 이는
곧 보행속도 및 보장, 보행지구력 감소 등의 문제를 유발한다.9-12

여러 가지 다차원적인 문제로 발생하는 뇌졸중 환자의 보행문제 는 독립적 삶을 영위함에 제한 요소가 되고 사회와 보호자에 대한 부 담과 의존으로 연결된다. ${ }^{13,14}$ 따라서 뇌졸중 환자가 지역사회에서 원 만하고 독립적인 삶을 영위하기 위해 충분한 보행능력을 갖추도록 하는 것은 중요하다. ${ }^{15}$ 임상에서는 뇌졸중 환자의 보행능력 향상을 위하여 일정한 리듬을 제공하여 보행훈련을 실시하는 리듬청각자 극 훈련법, ${ }^{16}$ 트레드밀 보행훈련법, ${ }^{17}$ 마비측으로의 체중 부하와 체중 이동 능력을 강조하기 위한 과제 지향적 훈련법 ${ }^{18}$ 로봇을 이용한 보 행훈련법, ${ }^{19}$ 보행에 사용되는 근육을 자극하기 위한 기능적 전기 자 극을 병행한 치료법 ${ }^{20}$ 등이 이루어지고 있다. 특히 운동학습과 운동 조절 능력의 향상을 위해 피드백 제공에 따른 보행훈련을 실시하여 보행능력에 미치는 영향에 대한 연구들이 이루어지고 있다..$^{21,22}$

뇌졸중 환자는 뇌 손상에 따른 운동조절의 문제가 발생하기 때문 에 보행능력 개선과 이와 관련된 운동학습을 위하여 보행훈련 동안
Received Mar 18, 2020 Revised Apr 3, 2020

Accepted Apr 14, 2020

Corresponding author Jin Park

E-mail mnipj1119@gmail.com
Copylight $(2020$ The Korean Society of Physical Therapy

This is an Open Access article distribute under the terms of the Creative Commons Attribution Non-commercial License (https:// creativecommons.org/license/by-nc/4.o.) which permits unrestricted non-commercial use, distribution, and reproduction in any medium, provided the original work is properly cited. 
피드백을 제공하는 것이 필요하다. 피드백이란 어떤 동작을 수행하 였을 때 움직임과 관련하여 정보를 제공하는 것을 뜻하는데, 움직임 과 관련하여 얻어지는 질적, 양적인 정보를 의미한다. ${ }^{23}$ 특히 피드백 종류 중 외재적 피드백은 외부에서 정보를 제공함으로써 움직임을 수정해 나갈 수 있도록 하며, 결과지식 피드백(knowledge of result)과 수행지식 피드백(knowledge of performance)으로 분류한다. ${ }^{23}$ 결과지 식 피드백은 수행과정의 결과에 대한 외부적인 정보를 제공하는 것 이고, 수행지식 피드백은 수행결과를 이끌어내는 움직임의 특징에 대한 정보를 제공하는 것을 의미한다.4

보행훈련 동안 외재적 피드백의 제공은 목표와의 차이를 인식하 게 함으로써 움직임을 스스로 수정해 나가도록 하여 운동학습을 촉 진시키고 보행능력을 개선할 수 있다. ${ }^{21}$ Druzbicki 등 25 의 연구에서는 외재적 피드백 중 결과지식 피드백을 제공함으로써 보장의 대칭성 향상에 효과적인 것으로 보고하였다. Lewek 등 26 의 연구에서도 시각 적 피드백과 고유수용감각 피드백 등의 결과지식 피드백을 제공하 여 시공간적 보행변수의 향상된 결과를 보고하였다. $\mathrm{Hsu}$ 등 ${ }^{27}$ 의 연구 에서는 뇌졸중 환자의 보행훈련 동안 마비측 골반 움직임의 조절을 위해 결과지식 피드백을 제공하여 골반이동의 대칭성을 향상시키고 보행능력을 향상시킨다고 보고하였다. 정신지체 성인을 대상으로 운 동학습을 위해 결과지식 피드백과 수행지식 피드백을 제공하는 것 에 따른 비교를 한 연구에서는 결과지식 피드백을 제공하는 것이 운 동학습을 촉진하는 것에 효과적임을 보고하였다. ${ }^{28}$

이렇게 결과지식 피드백과 수행지식 피드백 등의 외재적 피드백 제 공에 따른 보행훈련이 뇌졸중환자의 보행능력의 변화에 미치는 영 향에 대한 연구가 이루어져 있지만, 외재적 피드백 중 결과지식 피드 백과 수행지식 피드백을 각 각 제공하여 효과를 비교한 연구는 드문 실정이다. 따라서 본 연구에서는 뇌졸중 환자에게 트레드밀 보행훈 련 시 외재적 피드백 중 결과지식 피드백과 수행지식 피드백을 각 각 적용하여 어떠한 피드백의 유형이 뇌졸중 환자의 보행능력 개선을 위한 운동학습을 효과적으로 이끌어 낼 수 있는가에 대한 부분을 검 증하여 임상에서 트레드밀 보행훈련 시 효과적인 방법을 제공하기 위하여 실시하였다.

\section{연구 방법}

\section{1. 연구대상}

전주 D재활병원에서 재활운동치료를 받는 뇌졸중 환자 중 연구의 목적을 이해하고 연구에 참여하겠다고 동의한 24 명의 대상자에게 헬 싱키 선언에 입각하여 동의서를 받은 후 실시하였다. 제외조건에 포 함되는 대상자 5 명을 제외한 총 19 명의 대상자로 실시하였으며, 연구 대상자의 선정기준은 다음과 같았다.
Table 1. General characteristics of subjects

\begin{tabular}{lcc}
\hline & KR group $(\mathrm{n}=10)$ & KP group $(\mathrm{n}=9)$ \\
\hline Age $(\mathrm{yr})$ & $53.6 \pm 9.2$ & $51.9 \pm 10$ \\
Gender (Male/Female) & $7 / 3$ & $7 / 2$ \\
Time since stroke (Month) & $11.2 \pm 3.8$ & $11.4 \pm 3.9$ \\
Type of lesion & & \\
Hemorrhagic & 7 & 2 \\
Infarction & 3 & 7 \\
Side of lesion (Rt/Lt) & $3 / 7$ & $4 / 5$ \\
Height (cm) & $169.7 \pm 9.9$ & $168.2 \pm 9.7$ \\
Weight (kg) & $63.9 \pm 15.4$ & $64.1 \pm 7.3$ \\
K-MMSE (score) & $27.2 \pm 1.55$ & $26 \pm 1.41$ \\
\hline
\end{tabular}

Mean \pm standard deviation.

KR group: Knowledge of result feedback group, KP group: Knowledge of performance feedback group, K-MMSE: Korean version of mini-mental state examination.

뇌졸중 발병 후 6개월 이상 2년 미만인 자, 시각 및 청각에 장애가 없는 자, 하지에 보행에 영향을 줄 수 있는 정형외과적 문제가 없는 자, 한국판 간이 정신상태 검사(Korean version of mini-mental state examination; K-MMSE) 점수가 24점 이상으로 치료사의 지시사항을 따 를 수 있는 자, 6 분 동안 걷기 후 혈압, 맥박, 호흡의 이상이 없는 자, 트 레드밀 보행훈련이 가능한 자로 실시하였으며, 연구대상자의 제외조 건은 보행에 영향을 줄 수 있는 뇌졸중 이 외의 다른 신경학적 질환 을 가진 자와 편측무시를 가지고 있는 자는 제외하였다. 연구대상자 의 일반적 특성은 Table 1과 같으며 두 군 간 나이, 유병기간, 키, 몸무 게의 일반적 특성에는 통계학적 유의한 차이가 없었다( $\mathrm{p}>0.05)$.

\section{2. 실험방법}

1) 실험절차

연구에 앞서 대상자에게 제비뽑기를 실시하여 각 군에 무작위 배정 하였다. 연구대상자의 진단명, 나이, 성별, 손상부위, 유병기간 등을 대상자와의 면접과 의무기록을 통해 조사하여 두 군 간의 동질성을 확보하였다. 결과지식 피드백 제공에 따른 트레드밀 보행훈련 군 (knowledge of result feedback group; KR group)은 10명이었다. 수행지식 피드백 제공에 따른 트레드밀 보행훈련 군(knowledge of performance feedback group; KP group)은 9명이었다.

두 군 모두 30 분 동안 신경발달치료(neurodevelopmental therapy) 후, 30 분으로 구성된 보행훈련을 실시하였고 주 5 회, 총 3 주간 실시하 였다. 보행훈련을 시작하기 전 대상자들의 편안한 속도를 결정하기 위하여 지면에서 $10 \mathrm{~m}$ 의 거리를 표시해 두고 편안한 속도로 걷도록 하여 초시계로 측정한 후 대상자의 편안한 속도를 결정하였으며, 훈 련 전과 후 대상자의 보행능력 측정을 통해 보행훈련의 효과를 알아 보았다. 
(1) 결과지식 피드백 제공에 따른 트레드밀 보행훈련

트레드밀 보행훈련은 Biodex gait trainer 2 (Biodex Medical System Inc, $\mathrm{NY}, \mathrm{USA})$ 에서 실시하였다. 결과지식 피드백은 수행과정의 결과에 대한 외부적인 정보를 제공하는 것인데, 본 연구에서는 결과지식 피드백을 제공하기 위하여 트레드밀의 바닥면을 통해 인식되는 대상자의 마비측 과 비마비측의 보장이 화면에 표시되도록 하여 마비측과 비마비측의 보장이 대칭이 이뤼질 수 있도록 유도하였다. 보행훈련의 과정은 트레 드밀 발판 움직임에 적응하도록 하기 위하여 1 분간 피드백의 제공 없이 보행훈련을 실시하고, 10 분간 시각적 피드백의 제공하에 보행훈련을 실시하도록 하였다. 다시 1 분간 피드백 제공 없이 보행훈련을 실시한 후 에 피로도를 최소화하기 위하여 2분간 휴식하도록 하여 총 2회 실시하 였다. 훈련 후 산출된 마비측과 비마비측의 보장에 대한 값을 제시하여 다음 훈련 시 대칭을 이룰 수 있도록 피드백을 제시하였다

트레드밀 보행속도는 훈련 전 측정된 대상자의 편안한 속도에서 실시하였으며 주차별 속도를 점진적으로 증가시켜서 수행 가능한 경
우 증가된 속도에 맞춰 보행훈련을 실시하였다. 보행훈련 간 대상자 가 피로를 호소할 경우 휴식을 제공하여 대상자의 피로도를 최소화 하였고, 대상자의 안전을 위해 비마비측 손으로 트레드밀의 지지대 를 붙잡도록 하여 보행훈련을 실시하였으며 1 명의 치료사가 대상자 의 뒤에서 보조하였다(Figure 1A)

\section{(2) 수행지식 피드백 제공에 따른 트레드밀 보행훈련}

수행지식 피드백 제공에 따른 트레드밀 보행훈련 군은 보행훈련 동 안 시각적 피드백의 차단을 위하여 트레드밀의 화면에 마비측과 비 마비측의 보장이 나타나지 않게 하였다. 수행지식 피드백은 수행결 과를 이끌어내는 움직임의 특징에 대한 정보를 제공하는 것을 의미 하는데, 본 연구에서는 수행지식 피드백의 제공을 위하여 치료사는 마비측과 비마비측의 보장이 대칭이 이뤄질 수 있도록 “골반을 지지 하는 발로 옮기세요”라고 체중이동을 강조하는 구두지시를 하였다. ${ }^{29}$ 대상자는 정면을 응시하도록 하였으며, 훈련의 과정은 결과지식 피드백
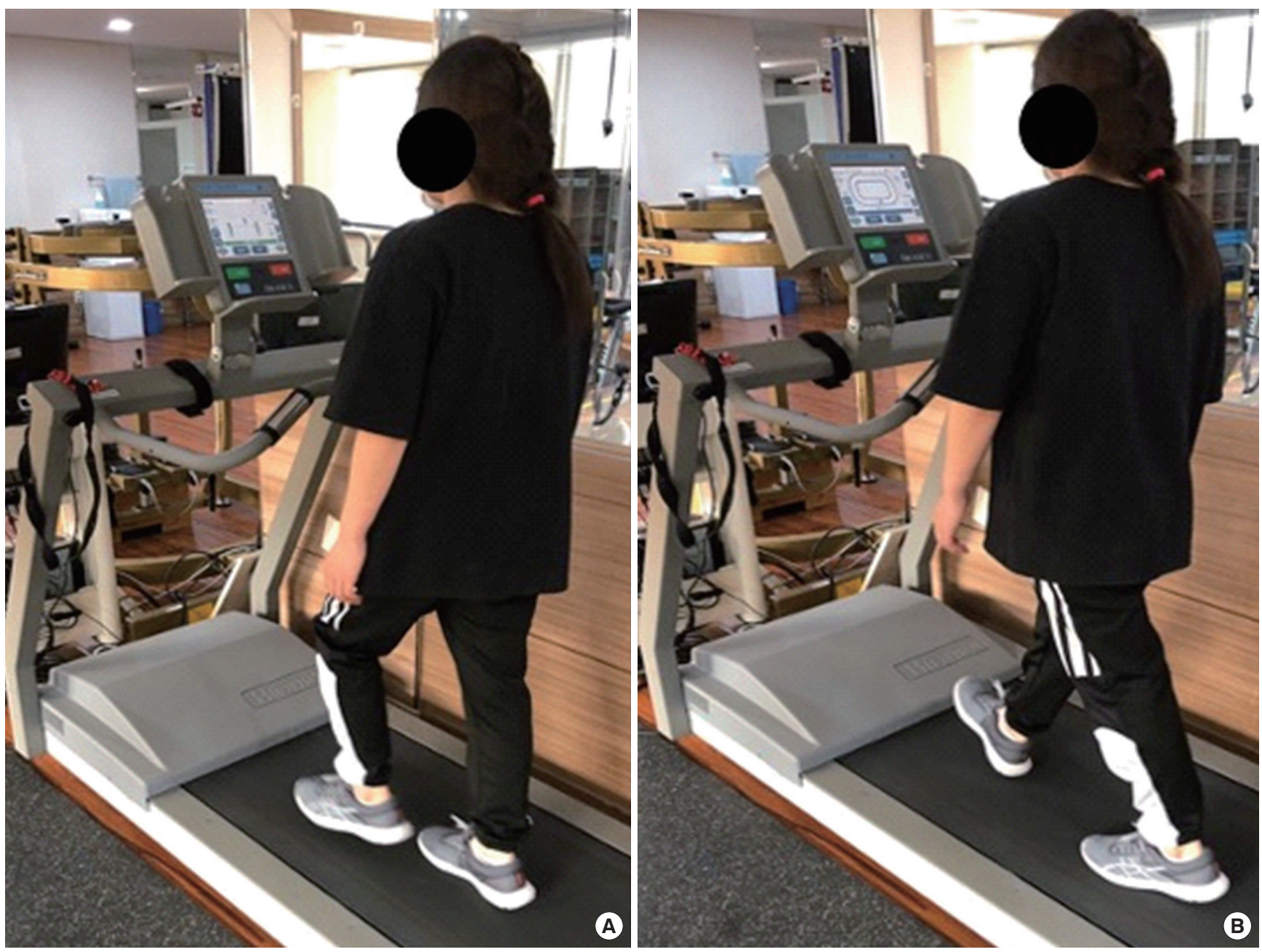

Figure 1. Treadmill training.

A: Knowledge of result feedback, B: Knowledge of performance feedback 
제공에 따른 트레드밀 보행훈련 군과 동일하게 실시하였다(Figure 1B).

\section{2) 보행평가}

대상자들의 중재 전과 후 시공간적 보행변수 변화를 측정하기 위해 보행분석기(Optogait, Microgate, Bolzano, Italy)를 사용하였다. 보행분 석기는 총 길이 $3 \mathrm{~m}, 2$ 개의 바와 2개의 Webcam (Webcam Pro 9000, Logitech, Taiwan)으로 구성되어있다. 2 개의 바에는 $1 \mathrm{~cm}$ 간격으로 적 외선 주파수를 통신하는 발광다이오드(LED)가 설치되어있어 송신 과수신을 할 수 있다.

2 개의 바를 $1.5 \mathrm{~m}$ 간격으로 설치하고 대상자들이 바 사이를 걷는 동안 발을 감지하여 시공간적 보행변수가 측정된다. 시작지점에 대상 자들이 대기한 상태에서 측정자의 “시작”이라는 구령과 동시에 편안 한 속도로 반대편을 향해 걷도록 교육하였다. 총 2 회 실시하여 시공 간적 보행변수에 대한 정보를 수집하였으며, 평균값을 사용하였다. 수집된 정보는 컴퓨터 소프트웨어(Optogait 1.6.4.0, MicrogateS.r.l, Italy)로 처리하였다. 보행분석기의 신뢰도는 .93-.99이다. ${ }^{30}$ 또한 대상자 들의 기능적 보행능력 평가를 위하여 기능적 보행 검사(Functional gait assessment, FGA)를 평가하였다. 이 검사는 낙상 위험이 높은 노인 을 평가하기 위하여 개발한 보행 평가 도구로써 안정성의 작은 변화 를 감지 할 수 있다. 기능적 보행능력을 평가 할 수 있는 10 개의 항목 으로 구성되어 있으며, 각 항목은 0 점에서 3 점까지의 4 점 척도로 점 수가 높을수록 기능적 보행 수행능력이 높음을 나타내고, 최대 점수 는 총 30 점이다. 이 검사는 뇌졸중 대상자에게도 적용하여 대상자의 기능적 보행 수행능력의 측정이 가능하며, 뇌졸중 대상자에게 적용 시 검사 재검사 신뢰도는 ICC $=.97$ 이고, 측정자 간 신뢰도는 $\mathrm{ICC}=.94$ 이다. ${ }^{31}$ 보행지구력 평가를 위하여 6 분 걷기 검사(6 meter walking distance test, $6 \mathrm{MWD}$ )는 치료실 내 $40 \mathrm{~m}$ 의 동일한 보행로의 바닥에 테이 프를 이용하여 $1 \mathrm{~m}$ 마다 표시를 해놓고, 초시계로 6 분을 미리 설정한 후 측정자의 “시작”이라는 구령에 맞추어 대상자들이 걷기를 시작하 도록 하였다. 6 분이 되었을 때 대상자들을 멈추도록 하여 보행거리를 측정하였으며, 측정된 거리가 멀리 이동한 대상자가 기능적 보행 수 행능력과 보행 지구력이 높았음을 나타낸다. 이 검사를 뇌졸중 대상 자에게 적용 시 검사 재검사 신뢰도는 $\mathrm{ICC}=.91$ 이고, 측정자 간 신뢰 도는 $\mathrm{ICC}=.97$ 이다. ${ }^{32}$

\section{3) 통계분석}

본 연구의 모든 통계적 분석은 PASW 22.0 (SPSS Inc., Chicago, IL, USA) 한글판을 이용하였고, KolmogorovSmirnov test에 의한 정규성검정을 실시하였다. 연구대상자의 일반적특성 동질성검사를 위하여 독립표 본 t-검정(independent ttest)을 실시하였다. 또한 각 군의 보행변수 전, 후 변화를 알아보기 위하여 대응표본 t-검정(paired ttest)을 실시하였
다. 군 간 보행변수의 변화량 차이를 알아보기 위하여 중재 전 값을 공변량으로 설정하고 공분산분석(analysis of covariance)을 실시하였 다. 유의수준은 0.05 로 하였다.

\section{결 과}

\section{1. 시공간적 보행변수의 실험 전, 후 변화비교}

중재 전 측정한 시공간적 보행변수에서는 두 군 간 유의한 차이가 없 었다( $\mathrm{p}>0.05)$. 두 군에서 모두 중재 전과 비교하여 중재 후 보행속도 와분속수가 통계학적으로 유의하게 향상되었다 $(\mathrm{p}<0.05)$. 군 간 비교 에서는 KR group의 보행속도와 분속수가 KP group과 비교하여 통계 학적으로 유의하게 빨라진 것으로 나타났다 $(\mathrm{p}<0.05)$.

비마비측 보장과 마비측 입각기 시간의 측정결과 KR group에서만 중재 후 통계학적으로 유의하게 향상되었다 $(\mathrm{p}<0.05)$. 군 간 비교에서 는 KR group에서 KP group과 비교하여 통계학적으로 유의하게 비마 비측 보장과 마비측 입각기 시간이 증가된 것으로 나타났다 $(\mathrm{p}<0.05)$ (Table 2).

Table 2. Comparison of pre and post training outcome measures of gait ability within and between groups

\begin{tabular}{|c|c|c|c|c|}
\hline & & $\begin{array}{l}\text { KR group } \\
(n=10)\end{array}$ & $\begin{array}{c}\text { KP group } \\
(n=9)\end{array}$ & $\mathrm{p}$ \\
\hline \multirow[t]{3}{*}{ Speed $(\mathrm{m} / \mathrm{s})$} & Pre & $0.55 \pm 0.09$ & $0.61 \pm 0.06$ & $0.04^{+}$ \\
\hline & Post & $0.67 \pm 0.07$ & $0.65 \pm 0.08$ & \\
\hline & $\mathrm{p}$ & $<0.001^{*}$ & $0.02^{*}$ & \\
\hline \multirow[t]{3}{*}{ Cadence (steps/min) } & Pre & $61.00 \pm 12.93$ & $69.44 \pm 15.81$ & $0.04^{+}$ \\
\hline & Post & $65.90 \pm 13.44$ & $71.56 \pm 15.60$ & \\
\hline & $\mathrm{p}$ & $<0.001^{*}$ & $<0.001^{*}$ & \\
\hline \multicolumn{5}{|l|}{ Step length (cm) } \\
\hline \multirow[t]{3}{*}{ Affected } & Pre & $47.00 \pm 12.11$ & $51.22 \pm 10.33$ & 0.20 \\
\hline & Post & $54.80 \pm 10.24$ & $54.89 \pm 10.04$ & \\
\hline & $\mathrm{p}$ & $<0.001^{*}$ & 0.07 & \\
\hline \multirow[t]{3}{*}{ Unaffected } & Pre & $38.40 \pm 9.99$ & $41.67 \pm 10.36$ & $<0.001^{*}$ \\
\hline & Post & $47.00 \pm 10.57$ & $44.78 \pm 15.20$ & \\
\hline & $\mathrm{p}$ & $<0.001^{*}$ & 0.10 & \\
\hline \multicolumn{5}{|l|}{ Stance time (\%) } \\
\hline \multirow[t]{3}{*}{ Affected } & Pre & $55.60 \pm 3.31$ & $55.11 \pm 2.98$ & $<0.001^{*}$ \\
\hline & Post & $59.60 \pm 1.84$ & $56.33 \pm 2.74$ & \\
\hline & $\mathrm{p}$ & $<0.001^{*}$ & 0.09 & \\
\hline \multirow[t]{3}{*}{ Unaffected } & Pre & $64.40 \pm 3.31$ & $63.78 \pm 2.68$ & 0.23 \\
\hline & Post & $61.80 \pm 1.69$ & $62.56 \pm 2.55$ & \\
\hline & $\mathrm{p}$ & $0.03^{*}$ & $0.02^{*}$ & \\
\hline
\end{tabular}

Mean \pm standard deviation.

KR group: Knowledge of result feedback group, KP group: Knowledge of performance feedback group.

${ }^{*} p<0.05$ : significant difference between pre and post intervention within the group, ${ }^{+} p<0.05$ : significant difference between the change values among the groups. 
Table 3. Comparison of pre and post training outcome measures of functional gait ability within and between groups

\begin{tabular}{llccc}
\hline & & KR group $(n=10)$ & KP group $(n=9)$ & $p$ \\
\hline FGA (score) & Pre & $21.20 \pm 2.86$ & $21.78 \pm 2.11$ & $0.01^{+}$ \\
& Post & $23.80 \pm 1.48$ & $22.89 \pm 1.45$ & \\
& $p$ & $<0.001^{*}$ & $0.01^{*}$ & \\
6MWD (m) & Pre & $157.60 \pm 67.38$ & $189.44 \pm 61.98$ & 0.06 \\
& Post & $169.70 \pm 64.03$ & $196.56 \pm 62.06$ & \\
& $p$ & $<0.001^{*}$ & $<0.001^{*}$ & \\
\hline
\end{tabular}

Mean \pm standard deviation.

KR group: Knowledge of result feedback group, KP group: Knowledge of performance feedback group.

${ }^{*} p<0.05$ : significant difference between pre and post intervention within the group, ${ }^{+} p<0.05$ : significant difference between the change values among the groups.

\section{2. 기능적 보행변수의 실험 전, 후 변화비교}

중재 전 측정한 기능적 보행변수에서는 두 군 간 유의한 차이가 없었 다(p>0.05). 기능적 보행변수 중 기능적 보행검사에 대한 중재 전후 비 교 결과, 두 군 모두 통계학적으로 유의하게 증가하였다 $(\mathrm{p}<0.05)$. 군 간 비교에서는 KR group 의 기능적 보행검사 점수가 KP group과 비교하 여 통계학적으로 유의하게 증가한 것으로 나타났다( $<<0.05)($ Table 3).

\section{고 찰}

본 연구에서는 뇌졸중 환자의 보행능력 향상을 위하여 트레드밀 보 행훈련 시 외재적 피드백 중 결과지식 피드백과 수행지식 피드백을 각 각 적용하여 어떠한 피드백의 유형이 뇌졸중 환자의 보행능력 개 선을 위한 운동학습을 효과적으로 이끌어 낼 수 있는가에 대한 부분 을 검증하였다.

그 결과 결과지식 피드백과 수행지식 피드백의 제공에 따른 트레 드밀 보행훈련은 보행속도와 분속수의 향상된 결과가 나타났다. 결 과지식 피드백과 수행지식 피드백은 외재적 피드백으로 분류하는데, 움직임과 관련된 정보를 외부에서 전달하여 수행할 수 있도록 하며, 보강적 피드백(augmented feedback)이라고도 한다. ${ }^{24}$ 선행연구에서는 시각적 피드백을 통한 외재적 피드백의 제공에 따른 보행훈련이 뇌 졸중 환자의 보행속도 향상과 분속수의 향상된 결과를 나타낸다고 보고하였다. 33,34 또한 보행훈련 동안 치료사의 구두지시를 통한 외재 적 피드백의 제공은 보행에 관여하는 근육의 활성도에 영향을 미치 게 되어 보행능력 향상을 이끌어 낸다고 보고하였다. ${ }^{29}$ 이는 뇌졸중 환자의 경우 운동과 감각능력 등의 문제로 인하여 운동학습 능력이 감소하기 때문에 외재적 피드백을 통한 운동과 감각능력의 보강이 운동학습 능력을 향상시킨 것에 따른 결과라 할 수 있다. 본 연구에서 도 결과지식 피드백과 수행지식 피드백을 제공한 두 군에서 모두 보 행속도와 분속수의 향상된 결과가 나타났는데, 운동학습 능력이 감
소된 뇌졸중 환자에게 외재적 피드백을 제공함으로써 운동과 감각 능력을 보완하고 운동학습을 이끌어내어 운동조절능력이 향상된 결과인 것으로 사료된다.

결과지식 피드백 제공에 따른 트레드밀 보행훈련 군은 수행지식 피드백 제공에 따른 트레드밀 보행훈련 군과 비교하여 보행속도, 분 속수, 비 마비측 보장의 증가, 마비측 기립시간의 증가의 결과가 나타 났다. 특히 마비측 기립시간의 증가에 따른 비 마비측 보장의 증가는 마비측과 비마비측의 대칭성이 향상되었음을 뜻한다. 선행연구에서 도 뇌졸중 환자에게 트레드밀 보행훈련 동안 시각적 피드백을 통한 결과지식 피드백의 제공은 마비측과 비마비측 보장의 대칭성과마비 측의 체중분포를 향상시키며 이를 통해 보행속도의 향상된 결과를 보고하였다. 26,35 이는 결과지식 피드백을 통한 구심성 정보가 신체적 인 반응을 이끌어내는 것에 따른 결과라고 할 수 있다. ${ }^{36}$ 정신지체 성 인의 운동 학습에 결과지식 피드백과 수행지식 피드백이 미치는 영 향에 대한 연구에서는 결과지식 피드백의 제공이 수행지식 피드백의 제공보다 빠르게 학습을 촉진하고 오래 유지 할 수 있도록 하기때문 에 운동학습을 촉진하기 위해서 피드백을 고려한다면 수행지식 피 드백 보다 결과지식 피드백이 효과적이라 보고하였다. ${ }^{28}$ 본 연구에서 도 결과지식 피드백 제공에 따른 트레드밀 보행훈련 군에서 수행지 식 피드백 제공에 따른 트레드밀 보행훈련 군과 비교하여 보행속도 와 분속수, 보행의 대칭성이 향상된 결과가 나타났는데, 새로운 구심 성 정보를 제공하는 것에 따른 신체적인 반응과 움직임을 개선하는 운동학습이 이루어진 결과로 생각된다. 구두지시를 통한 수행지식 피드백은 보행훈련 동안의 근 활성이나 관절의 움직임에 영향을 미 칠 수 있다. ${ }^{29}$ 그러나 Ploughman 등 ${ }^{29}$ 의 연구와 본 연구에서는 결과지 식 피드백 제공에 따른 트레드밀 보행훈련 군과 비교하여 시공간적 보행변수에는 영향을 미치지 않는 것으로 나타났는데, 이는 구두지 시로 피드백이 제공되기 때문에 움직임을 수행함에 있어 정확한 목 표가 존재하지 않아 정확한 목표가 제시되는 결과지식 피드백 제공 에 따른 트레드밀 보행훈련 군과의 차이가 나타난 것으로 사료된다.

기능적 보행검사와 6 분 걷기 검사는 대상자의 시공간적 보행요소 중 보행속도, 분속수, 보장 등의 영향을 받는다. 본 연구에서 기능적 보행능력을 알아보기 위해 실시한 기능적 보행검사 결과 결과지식 피드백 제공에 따른 트레드밀 보행훈련 군이 수행지식 피드백 제공 에 따른 트레드밀 보행훈련 군과 비교하여 향상된 것으로 나타났다. 이는 앞서 나왔던 결과를 바탕으로 결과지식 피드백 제공에 따른 보 행훈련을 실시하는 것이 수행지식 피드백을 제공하여 보행훈련을 실 시하는 것보다 보행속도와 분속수, 비마비측 보장의 향상, 마비측 입 각기 시간의 증가된 결과가 나타났기 때문에 보행 대칭성이 향상된 것에 따른 결과로 생각된다. 이를 통해 트레드밀 보행훈련 시 결과지 식 피드백을 제공하는 것이 뇌졸중 환자의 시공간적 보행변수와 기 
능적 보행능력 향상에 더 효과적이라 할 수 있다.

본 연구에서는 수행지식 피드백의 제공을 위하여 연구자의 구두 지시를 제공하였다. Ploughman 등 29 의 연구에서는 구두지시를 통한 수행지식 피드백의 제공은 보행훈련 동안 보행에 필요한 근육의 활 성과 관절움직임의 변화를 이끌어 낸다고 하였다. 이는 보행훈련 동 안 제공되는 수행지식 피드백에 맞춰 움직임을 수정하려는 과정에서 나타난 결과라 보고하였다. 그러나 본 연구에서는 연구자의 구두지 시에 맞춰 보행훈련을 실시하는 것에 따른 대상자가 제대로 수행하 고 있는가에 대한 정확한 판단이 어려우며, 결과지식 피드백과의 양 적인 측면에서 차이가 있을 수 있다. 따라서 수행지식 피드백으로 구 두지시를 제공하고자 한다면 대상자가 움직임을 피드백에 맞춰 수정 하고 있는가에 대한 기준이 필요하며, 여러 방법으로 운동학적 정보 를 제공하는 것에 따른 학습자의 집중력이 필요하다. 또한 본 연구에 서는 시공간적 보행변수만 확인하였기 때문에 균형능력이나 운동형 상학적 보행변수의 평가가 필요하다. 본 연구의 연구기간은 3주간의 중재 후 효과만 측정하였기 때문에 치료의 효과가 지속적으로 유지 되었는가에 대한 확인은 이루어지지 않았다. 추후에는 더 많은 대상 자와 함께 오랜 기간의 연구가 필요할 것이다.

뇌졸중 환자에게 트레드밀 보행훈련 시 결과지식 피드백을 제공 하는 것은 수행지식 피드백을 제공하는 것보다 보행속도와, 분속수, 비마비측의 보장, 마비측 입각기 시간, 기능적 보행 검사의 향상된 결 과를 나타냈다. 이는 트레드밀 보행훈련 동안 구두 지시로 이루어지 는 수행지식 피드백 보다는 목표가 명확한 결과지식 피드백의 새로 운 구심성 정보에 맞춰 효과적으로 운동학습이 이루어진 것에 따른 결과라 할 수 있다. 따라서 임상에서 트레드밀 보행훈련을 실시하고 자 한다면 수행지식 피드백을 제공하는 것보다 결과지식 피드백을 제공하는 것을 권장한다.

\section{REFERENCES}

1. Peurala SH, Kononen P, Pitkanen K et al. Postural instability in patients with chronic stroke. Restorative Neurology and Neuroscience. 2007; 25(2):101-8.

2. Lamontagne A, De Serres SJ, Fung J et al. Stroke affects the coordination and stabilization of head, thorax and pelvic during voluntary horizontal head motions performed in walking. Clinical Neuro Physiology. 2005; 116(1):101-11.

3. Mercier L, Audet T, Hebert R et al. Impact of motor, cognitive, and perceptual disorders on ability to perform activities of daily living after stroke. Stroke. 2001;32(11):2602-8.

4. Januario F, Campos I, Amaral C. Rehabilitation of postural stability in ataxic/hemiplegic patients after stroke. Disabil Rehabil. 2010;32(21): 1775-9.

5. Nyberg L, Gustafson Y. Patient falls in stroke rehabilitation. a challenge to rehabilitation strategies. Stroke. 1995;26(5):838-42.

6. Sharp SA, Brouwer BJ. Isokinetic strength training of the hemiparetic knee: effects on function and spasticity. Arch Phys Med Rehabil. 1997; 78(11):1231-6.

7. Jung T, Lee D, Charalambous C, Vrongistinos K. The influence of applying additional weight to the affected leg on gait patterns during aquatic treadmill walking in people poststroke. Arch Phys Med Rehabil. 2010; 91(1):129-36.

8. Kim CM, Eng JJ. Symmetry in vertical ground reaction force is accompanied by symmetry in temporal but not distance variables of gait in persons with stroke. Gait Posture. 2003;18(1):23-8.

9. Balasubramanian CK, Bowden MG, Neptune RR et al. Relationships between step length asymmetry and walking performance in subjects with chronic heparesis. Arch Phys Med Rehabil. 2007;88(1):43-9.

10. Bowden MG, Balasubramanian CK, Neptune RR et al. Anterior-posterior ground reaction forces as a measure of paretic leg contribution in hemiplegic walking. Stroke. 2006;37(3):872-6.

11. Patterson SL, Forrester LW, Rodgers MM et al. Determinants of walking function after stroke: differences by deficit severity. Arch Phys Med Rehabil. 2007;88(1):115-9.

12. Von Schroeder HP, Coutts RD, Lyden PD et al. Gait parameters following stroke: a practical assessment. J Rehabil Res Dev. 1995;32(1):25-31.

13. Lau KW, Mak MK. Speed-dependent treadmill training is effective to improve gait and balance performance in patients with sub-acute stroke. J Rehabil Med. 2011;43(8):709-13.

14. Lord SE, McPherson K, McNaughton HK et al. Community ambulation after stroke: How important and obtainable is it and what measures appear predictive?. Arch Phys Med Rehabil. 2004;85(2):234-9.

15. Hase K, Suzuki E, Matsumoto M et al. Effects of therapeutic gait training using a prosthesis and a treadmill for ambulatory patients with hemiparesis. Arch Phys Med Rehabil. 2011;92(12):1961-6.

16. Mainka S, Wissel J, Voller $\mathrm{H}$ et al. The use of rhythmic auditory stimulation to optimize treadmill training for stroke patients: a randomized controlled trial. Front Neurol. 2018;9:755.

17. Madhavan S, Lim H, Sivaramakrishnan A et al. Effects of high intensity speed-based treadmill training on ambulatory function in people with chronic stroke: a preliminary study with long-term follow-up. Sci Rep. 2019;9(1):1985

18. Jeong YG, Koo JW. The effects of treadmill walking combined with obstacle-crossing on walking ability in ambulatory patients after stroke: a pilot randomized controlled trial. Top Stroke Rehabil. 2016;23(6):40612.

19. Ham SC, Lim CG. The effects of robot-assisted gait training with visual feedback on gait, balance and balance confidence in chronic stroke patients. J Kor Phys Ther. 2016;28(2):71-6.

20. Allen JL, Ting LH, Kesar TM. Gait rehabilitation using functional electrical stimulation induces changes in ankle muscle coordination in stroke survivors: a preliminary study. Front Neurol. 2018;9:1127.

21. Genthe K, Schenck C, Eicholtz S et al. Effects of real-time gait biofeedback on paretic propulsion and gait biomechanics in individuals poststroke. Top Stroke Rehabil. 2018;25(3):186-93.

22. Yu KH, Kang KY. Functional electrical stimulation with augmented feedback training improves gait and functional performance in individuals with chronic stroke: a randomized controlled trial. J Kor Phys Ther. 
2017;29(2):74-9.

23. Schmidt RA, Young DE. Methodology for motor learning: a paradigm for kinematic feedback. J Mot Behav. 1991;23(1):13-24.

24. Shumway-Cook AS, Woolacott MH. Motor control: translating research into clinical practice. 4th ed. Lippincott Williams \& Wilkins, Philadelphia, 2012.

25. Druzbicki M, Guzik A, Przysada G et al. Efficacy of gait training using a treadmill with and without visual biofeedback in patients after stroke: A randomized study. J Rehabil Med. 2015;47(5):419-25.

26. Lewek MD, Feasel J, Wentz E et al. Use of visual and proprioceptive feedback to improve gait speed and spatiotemporal symmetry following chronic stroke: a case series. Phys Ther. 2012;92(5):748-56.

27. Hsu CJ, Kim J, Wu M. Combined Visual Feedback with Pelvic Assistance Force Improves Step Length during treadmill walking in Individuals with Post-Stroke Hemiparesis. Conf Proc IEEE Eng Med Biol Soc. 2018; 2018:2333-6.

28. Kim WH, Jeon BJ. Effect of Knowledge of Results and Performance on Motor Learning in Adult with Mental Retardation. Korea J Occup Ther. 2005;13(2):31-9.

29. Ploughman M, Shears J, Quinton S et al. Therapists' cues influence lower limb muscle activation and kinematics during gait training in subacute stroke. Disabil Rehabil. 2018;40(26):3156-63.

30. Lienhard K, Schneider D, Maffiuletti NA et al. Validity of the optogait photoelectric system for the assessment of spatiotemporal gait parameters. Med Eng Phys. 2013;35(4):500-4.

31. Thieme H, Ritschel C, Zange C. Reliability and validity of the functional gait assessment (German version) in subacute stroke patients. Arch Phys Med Rehabil. 2009;90(9):1565-70.

32. Hamilton DM, Haennel RG. Validity and reliability of the 6-minute walk test in a cardiac rehabilitation population. J Cardiopulm Rehabil. 2000; 20(3):156-64.

33. Pavare Z, Garuta I, Ananjeva T et al. Gait rehabilitation of post-stroke patients by treadmill gait training with visual feedback. Gait \& Posture. 2015;1(42):S69-S70.

34. Broderick P, Horgan F, Blake C et al. Mirror therapy and treadmill training for a patient with chronic stroke: A case report. Physiotherapy theory and practice. 2018;35(5):1-11.

35. Hollands KL, Pelton TA, Wimperis A et al. Feasibility and preliminary efficacy of visual cue training to improve adaptability of walking after stroke: Multi-centre, single-blind randomised control pilot trial. PLoS One. 2015;10(10):e0139261.

36. Brasileiro A, Gama G, Triqueiro L et al. Influence of visual and auditory biofeedback on partial body weight support treadmill training of individuals with chronic hemiparesis: A randomized controlled clinical trial. Eur J Phys Rehabil Med. 2015;51(1):49-58. 